\title{
FORMAR EN RECREACIÓN, UN SUEÑO 0 UNA REALIDAD
}

\section{Astrid Bibiana Rodríguez Cortés ${ }^{1}$}

La formación en recreación para algunos resulta una utopía, compleja, difícil y de poca sustentación, sin embargo, desde hace ya muchos años, con los Planes Nacionales de Recreación se había venido sosteniendo que era necesario cualificar y formar al talento humano que comprendiera que la intervención en recreación necesita una mirada holística e integral que propenda por el desarrollo humano (Pineda y Osorio, 2000).

Por más de cuarenta años se vienen realizando procesos sistemáticos de intervención de la recreación en distintos espacios del país, no obstante, todavía pareciera no reconocerse el esfuerzo realizado. Aún así, la recreación ha mostrado un fuerte impacto social, que ha permitido su sostenibilidad frente a los problemas presupuestales, de opinión o de oportunidad política.

En muchos ámbitos ha encontrado tropiezos para su desarrollo, uno y el más fuerte, es el imaginario social, el cual ha concebido la recreación como un tema pasajero y de poca trascendencia social y personal. Luchar contra ello se ha convertido en una labor titánica donde el poder del argumento ha logrado penetrar y causar efectos muy lentos pero de gran impacto. Muestra de ello son los Planes Nacionales de Recreación, la inclusión y reconocimiento constitucional, los planes y programas que de orden privado y público se realizan y la formación universitaria especializada, lo cual permite el fortalecimiento conceptual y de intervención práctico que este campo requiere.

En este sentido, se puede encontrar una oferta interesante en el campo de la formación en recreación como son cursos de carácter informal, colegios con media especializada, técnicos y tecnólogos, profesionales y Licenciados en Recreación.

\section{Una experiencia de formación en el campo de la recreación}

Pero, ¿qué significa entonces, formar Licenciados en Recreación?, desde el panorama expuesto, se puede decir que la tarea no es sencilla, modificar el imaginario social, ha sido uno de los obstáculos más difíciles de vencer. De por sí abrir caminos nuevos, no es fácil, cotidianamente se enfrentan preguntas como: ¿eso se estudia?, ¿eso es una carrera?, ¿es posible en pensar en ello como una opción laboral consistente y pertinente?

Nos hemos acostumbrado entonces a justificar nuestro que hacer, mostrar como en la situación actual se requieren otro tipo de saberes de los usualmente conocidos, de abrir la mirada al campo laborar, de informar sobre el proceso de consolidación que como campo tiene la recreación, todo ello es cotidiano en la Licenciatura de la Universidad Pedagógica Nacional que desde el año 2006 se ha dado a la tarea de formar Licenciados en Recreación, desde unos preceptos como son la pedagogía como fundamento del desarrollo humano que con intervenciones sociales responsables, dejan ver que esta carrera tiene un presente y un futuro en este país, donde con una situación social convulsionada, se requieren espacios de transformación social y cultural, en el cual el espíritu de la solidaridad y no de la competitividad reinen, donde la equidad social y no la exclusión puedan encontrar sentido y significado, donde el pensamiento creativo y divergente lleve a cabo toda su posibilidad de expresión, en definitiva una nueva posibilidad de ser, de pensar, y de sentir sean posibles, donde el juego, la broma, el desafío, el reto, la expresión, sean parte de la formación personal y profesional.

\footnotetext{
${ }^{1}$ Profesora de Planta de la Universidad Pedagógica Nacional. Facultad de Educación Física, Coordinadora Licenciatura en Recreación. abrodriguez@pedagogica.edu.co
} 
Desde la alegría, la risa, el miedo, la angustia, se convoca a una licenciatura, a pensar una propuesta de desarrollo humano, distinta, posible, plausible para un mundo mejor, donde la formación docente está centrada en el análisis cotidiano del ser a partir de situaciones y prácticas habituales.

Algunos de los conocimientos que se adquieren son: el juego como fundamento y no como didáctica, la construcción o reconstrucción del tejido social a partir de la intervención recreativa, la preservación de la identidad cultural desde el reconocimiento de fiestas, ferias, carnavales y todas las posibilidades lúdicas que se tiene para conservar y mostrar, se estudia el sentido de educar en la escuela rescatando los rincones lúdicos y de juego para reconocer en ellos la posibilidad de encuentro de unos y otros, acercamiento a la práctica de la actividad física como un medio para disfrutar, gozar, reconocerse y compartir, aproximación al arte y su apreciación donde se busca el encuentro personal y crecimiento cultural, y el eje transversal a todo ello, es comprender que la recreación se encuentra en el campo de la educación y la pedagogía que propende por una formación cada día más humana.

Se pretende entonces, que este licenciado en formación y futuro profesional tenga la capacidad de proponer, promover y propiciar espacios con características alternativas, alterativas e incluyentes, no sólo como eslogan sino como realidad. Formar en recreación sigue siendo un sueño, pero en la Universidad Pedagógica Nacional es una realidad con todos los bemoles que ello implica, aún es largo el camino que queda por recorrer, pero se está avanzando en ello, el compromiso social en la formación específica en recreación es una travesía que apenas comienza, pero como cuando algo empieza, queda mucho por construir, mucho por pensar y seguir fantaseando.

\section{Referencias}

Pineda, N., Osorio, E. (2000). 'Plan Nacional de Recreación 1999-2002'. Obtenido el 25 de Octubre de 2010, desde: http://www.redcreacion.org/relareti/documentos/programa_nal_formacion.html 